\title{
Childhood eating disorders: British national surveillance study*
}

Dasha E. Nicholls, Richard Lynn and Russell M. Viner

\section{Background}

The incidence of eating disorders appears stable overall, but may be increasing in younger age groups. Data on incidence, clinical features and outcome of early-onset eating disorders are sparse.

\begin{abstract}
Aims
To identify new cases of early-onset eating disorders $(<13$ years) presenting to secondary care over 1 year and to describe clinical features, management and 1-year outcomes.
\end{abstract}

\section{Method}

Surveillance over 14 months through the established British Paediatric Surveillance System, and a novel child and adolescent psychiatry surveillance system set up for this purpose.

\section{Results}

Overall incidence was 3.01/100 000 (208 individuals). In total $37 \%$ met criteria for anorexia nervosa; $1.4 \%$ for bulimia nervosa; and $43 \%$ for eating disorder not otherwise specified. Nineteen per cent showed determined food avoidance and underweight without weight/shape concerns. Rates of comorbidity were $41 \%$; family history of psychiatric disorder 44\%; and early feeding difficulties $21 \%$. Time to presentation was $>8$ months. A total of $50 \%$ were admitted to hospital, typically soon after diagnosis. Outcome data were available for $76 \%$ of individuals. At 1 year, $73 \%$ were reported improved, 6\% worse and 10\% unchanged (11\% unknown). Most were still in treatment, and seven were hospital in-patients for most of the year.

\section{Conclusions}

Childhood eating disorders represent a significant clinical burden to paediatric and mental health services. Efforts to improve early detection are needed. These data provide a baseline to monitor changing trends in incidence.

\section{Declaration of interest}

None.
Epidemiological studies suggest that although the incidence of eating disorders has been fairly static over the last few decades, ${ }^{1,2}$ individuals with anorexia nervosa are presenting at an earlier age. ${ }^{3,4}$ Current knowledge about childhood or early-onset eating disorders (defined here as onset before 13 years of age) has been largely derived from clinical case series from specialised settings. $^{5-11}$ Accurate estimates of clinical case numbers and information about natural history and prognosis is needed to plan and coordinate developmentally appropriate services for this patient group, as advocated in clinical guidelines. ${ }^{12}$ General mental health screening is generally poor at picking up eating disorders, ${ }^{13}$ the diagnosis of which require self-report of highly specific cognitions and behaviours, corroborated by physical findings and, in children, by parental report. ${ }^{14}$ In addition, incomplete involvement of those with eating disorders in population-based research is difficult to interpret. ${ }^{15}$ General practitioner (GP) registers are commonly used to identify cases, ${ }^{1,4}$ but the recognition of eating disorders in children by GPs can be poor. ${ }^{16}$ Eating disorders in prepubertal and peripubertal children frequently require paediatric admission and long-term medical monitoring as well as psychiatric management. In the UK they are likely to present to paediatricians as well as to child psychiatrists. ${ }^{9}$ Surveillance is well established as an effective methodology for the identification of rare disorders or events of clinical significance, ${ }^{17}$ and does not rely on patient consent for case ascertainment.

Our objectives in this study were to estimate the incidence of early-onset eating disorders in children presenting to secondary

*Parts of this paper were presented at the Annual Conference of the Royal College of Paediatrics and Child Health in York, April 2007, and at the Royal College of Psychiatrists' Child and Adolescent Psychiatry Annual residential conference in September 2008. care in the British Isles; describe the age, gender and family history, clinical features at presentation including psychiatric comorbidity and identify aspects of current management, including hospitalisation; explore the validity of current diagnostic groupings for childhood eating disorders and to assess outcome at 1 year.

\section{Method}

Individuals with early-onset eating disorders were notified for a period of 14 months (March 2005 and May 2006), through two linked surveillance systems. The British Paediatric Surveillance Unit (BPSU) inquiry system is well accepted for the study of rare conditions. Consultant paediatricians throughout the British Isles (United Kingdom (UK) and Republic of Ireland (ROI)) return monthly notification cards for a series of rare conditions; approximately $93 \%$ of paediatricians respond each month (see http://bpsu.inopsu.com/). For this study, a separate system for surveillance of notification by psychiatrists, the Child and Adolescent Psychiatric Surveillance System, was established using similar methodology.

In each system, details of cases were obtained from a questionnaire completed by the notifying paediatrician or child and adolescent psychiatrist. Follow-up data were obtained from clinicians at 1 year. The case definition was designed to encourage over- rather than underreporting, and duplicate case reporting was encouraged. The response rate for paediatricians was $93 \%$ and for child and adolescent psychiatrists was $85 \%$.

The study was approved by the BPSU Executive and the National Research Ethics System. Patient Information Advisory Group Section 60 exemption approval for this study was obtained 
(PIAG/BPSU 2-10(H)/2005) for notification without the need for consent from children or families.

\section{Case definition}

The case definition was based on modified DSM-IV ${ }^{18}$ and ICD $-10^{19}$ criteria for eating disorders, and approved by the BPSU Executive Committee. Developmental considerations ${ }^{20}$ in the case definition and questionnaire included: a focus on behaviours and preoccupations rather than specific cognitions; omission of amenorrhoea, since most would be premenarcheal; recognition that weight loss may manifest as failure in weight gain in this age group; and no binge frequency was specified or operational definition of bingeing used, since access to food can limit bingeing in this age group. The instruction used for notification was:

Please report any child aged 5 to 12 years inclusive seen in the last month, with two or more of the following

- weight loss or failure to gain weight during a period of expected growth, not due to any identifiable organic cause

- determined food avoidance

- fear of weight gain

- preoccupation with body weight or energy intake

- self induced vomiting

- excessive exercisinga

- recurrent episodes of binge eating or abuse of laxatives

axercise may be considered to be excessive when it significantly interferes with important activities, when it occurs at inappropriate times or in inappropriate settings, or when the individual continues to exercise despite injury or other medical complications. ${ }^{18}$

Consultants who notified potential cases were then asked to complete a data form from which the authors identified eligible individuals and their diagnoses. Confirmed cases meeting the case definition were grouped by eating disorder subtype using operational criteria based on symptoms reported in the questionnaire (Appendix). Clinician report of comorbidity was noted.

Follow-up took the form of data collection at 12 months after notification through a questionnaire mailed to reporting clinicians.

\section{Analysis}

Analyses were primarily descriptive. Where duplicates were reported, data were used from the most complete data-set, or the data-set closest to the reporting date. Incidence was calculated as number of cases/total children of that age in the population (UK plus ROI) expressed as per 100000 population, using data for the total population of children for 2005 aged 5-13 obtained from the Office of National Statistics (UK) and the Central Statistics Office (Ireland). Nutritional status was determined by calculating body mass index (BMI) from weight and height, then converting to \% of median BMI for age and gender using UK BMI reference data. ${ }^{21}$ Underweight was defined as $<85 \%$ BMI for age and gender, based on the criteria used for diagnosis of anorexia nervosa $^{18}$ and the World Health Organization definition of malnutrition. ${ }^{22}$ To investigate the validity of eating disorder diagnoses in this age group, principal-components analysis was used to identify clusters of symptoms, using eigen values greater than one as a threshold. Analyses were performed using Microsoft Excel and SPSS version 15 on Windows.

\section{Results}

Figure 1 shows a flow diagram of case reporting. Of 505 suspected cases, $380(75 \%)$ were reported by psychiatrists and $125(25 \%)$ by paediatricians. A total of $78(15 \%)$ potential cases had to be excluded as insufficient data were obtained to judge eligibility. For 427 suspected cases with sufficient data, 124 (29\%) were judged to be reporting errors. The majority of these were for individuals where the age was outside the reporting range or that presented prior to the reporting period, making them prevalent rather than incident cases. Of 303 notifications that met inclusion criteria, 95 (31\%) were duplicate notifications, leaving 208 early-onset eating disorder cases as the sample for analysis.

\section{Incidence}

Notification of 208 cases during the study period provides an overall incidence estimate of 3.01/100000 (95\% CI 2.6-3.5). Figure 2 shows incidence by age for the overall group and for each eating disorder category. There was a clear relationship between incidence and increasing age. There were no cases identified for individuals aged 5 years. The overall incidence age $6-7$ years was $0.21 / 100000$ (95\% CI $0.01-0.88)$; at age $7-8$ years was $0.21 / 100000$ (95\% CI $0.01-0.89$ ); at $8-9$ years was $0.92 / 100000$ (95\% CI $0.28-1.66)$; at $9-10$ years was $1.64 / 100000$ (95\% CI $0.89-2.84$ ); at $10-11$ years was $3.56 / 100000$ (95\% CI $2.3-4.99$ ); at 11-12 years was $4.46 / 100000$ (95\% CI 3.12-6.17); and at 12-13 years was 9.51/100 000 (95\% CI 7.5-11.9).

Using the operational definitions in the Appendix, 76 individuals were classified as having anorexia nervosa (overall incidence 1.09/100000); 3 with bulimia nervosa (incidence $0.04 / 100000$ ); and 89 with eating disorder not otherwise specified (EDNOS) (incidence 1.22/100000), of which 6 showed binge eating but no compensatory behaviours, hereafter called binge eating disorder (incidence 0.09/100 000) (Fig. 2). Forty individuals met the case definition, but did not have weight and shape concerns or fear of weight gain (defined as 'other'; incidence $0.58 / 100000)$.

\section{Demographics and medical status}

Of the 208 individuals identified, 171 (82\%) were female and 37 (18\%) male. Of the anorexia nervosa group $12 \%$ were boys, rising to $18 \%$ of the EDNOS group and to $33 \%$ of the 'other' group. In total, $86 \%$ were White British, 2.5\% Irish, 5\% Asian/Asian mixed ethnicity and $1 \%$ Black/Black mixed ethnicity. The mean age was 11.5 years $($ s.d. $=1.3)$, with a reported mean duration of illness of 8.3 months prior to presentation.

Of all the boys and girls, 59\% were fully prepubertal, $27 \%$ in early/mid-puberty, $8 \%$ were in late puberty and $6 \%$ unknown. Menarcheal status was known in 161 of 171 girls; 123 (76\%) were premenarcheal. Of the 38 girls known to be postmenarcheal, 23

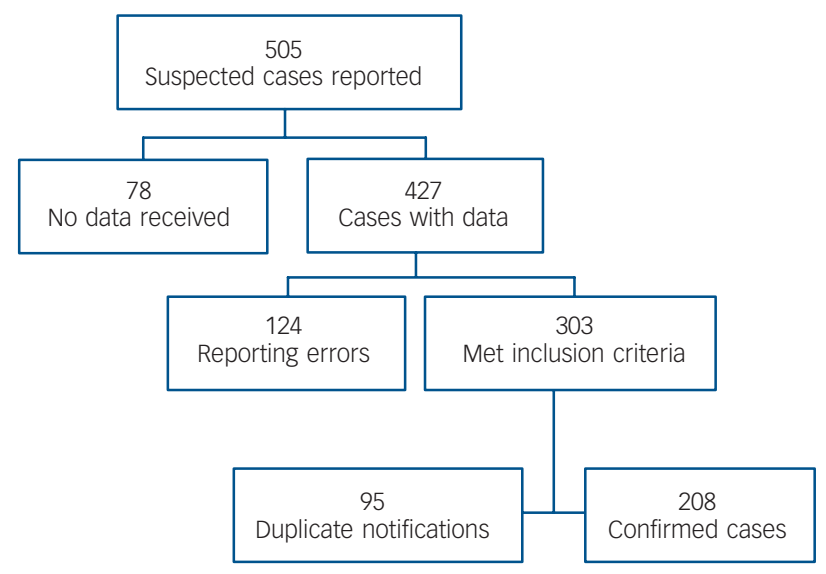

Fig. 1 Flow diagram of case ascertainment. 


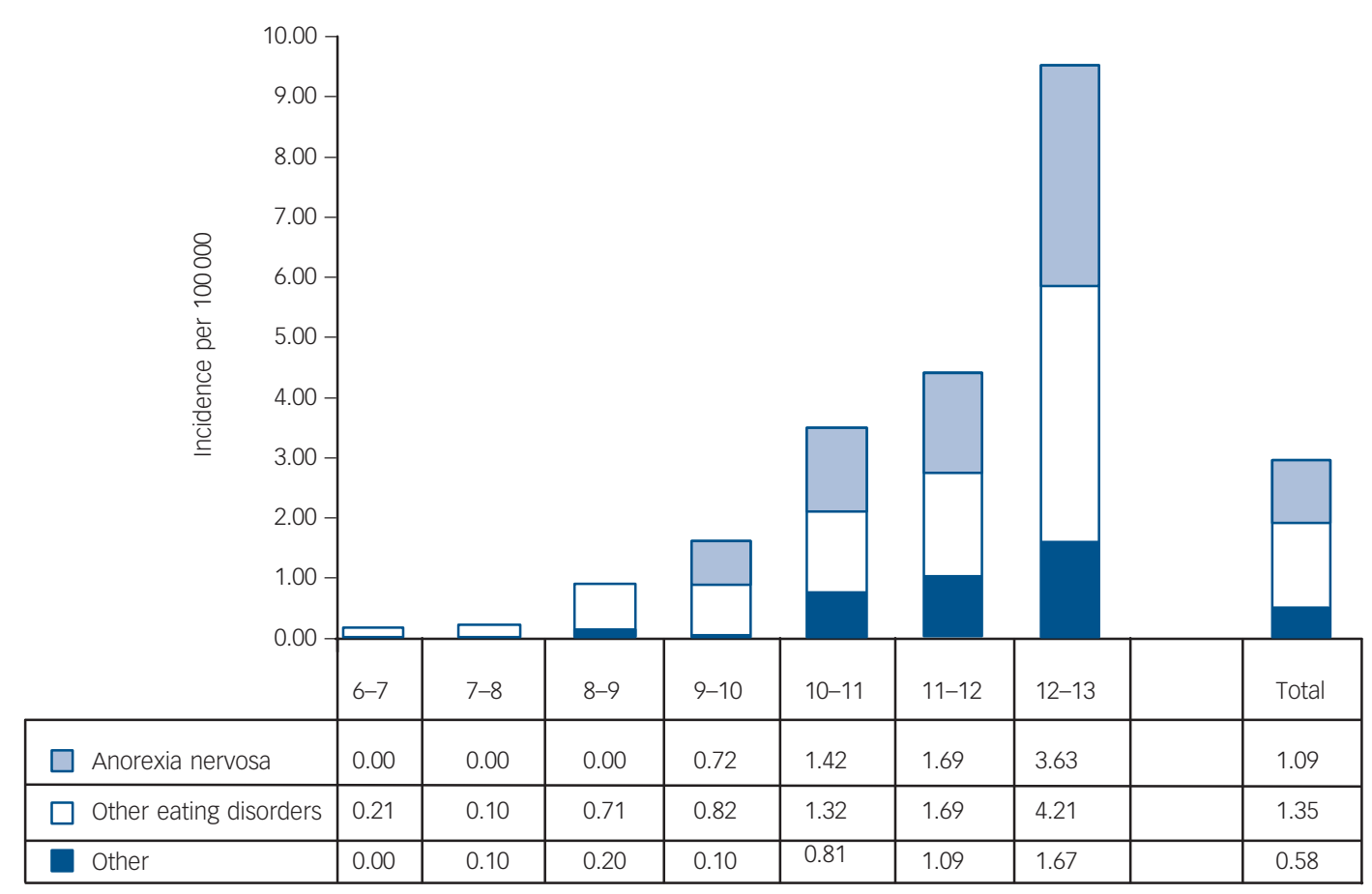

Fig. 2 Incidence by age at onset and diagnosis.

Other eating disorders include all other eating disorders (bulimia nervosa, eating disorder not otherwise specified, binge eating disorder); 'other' category includes individuals meeting definition for clinically significant eating difficulty, not currently classifiable as an eating disorder.

had amenorrhea, 8 did not and the remainder was unknown or not reported.

By definition, individuals with anorexia nervosa were underweight (mean 77\% BMI for age), but \% BMI in this group was not lower than for the 'other' group, whose mean \% BMI was $79 \%$. The six individuals classified with binge eating disorder were overweight, with a mean \% BMI of $144 \%$.

\section{Family and early history}

For $44 \%$ of individuals there was a close family member with a history of psychiatric disorder and for $12 \%$ more than one family member was affected. The proportion did not vary across diagnostic groups. Anxiety and depression accounted for almost $70 \%$ of the family history of mental health problems. Obsessivecompulsive disorder (OCD), anxiety disorder, psychosis, substance misuse and neurodevelopmental disorders were also represented.

Of 186 individuals in whom gestation was reported, only 2 were less than 36 weeks premature. A history of early feeding problems was reported in around $21 \%$ (66\% none, $13 \%$ unknown), across all diagnoses (range 17-26\%). The majority of feeding difficulties reported (as free text) were picky, fussy or faddy eating, and restrictive eating (eating small quantities). Comments were made highlighting specific features or severity (for example 'fussy to 9 years'; 'milk only until age 3'; 'at 3-4 still eating liquids, could not tolerate lumps, not aware of hunger').

\section{Symptom profiles}

Determined food avoidance was the most common symptom, occurring in $96 \%$ of all individuals. Other symptoms were morbid preoccupation with food (84\%), fear of weight gain $(71 \%)$, preoccupation with body weight $(67 \%)$, preoccupation with body shape $(51 \%)$, excessive exercising (43\%), somatic complaints
(31\%), self-induced vomiting (19\%), binge eating (5\%) and laxative or diuretic use (1\%). There was $71 \%$ concordance in preoccupation with body weight and with body shape. Weight concerns were more common in the absence of shape concerns than vice versa.

Principal-components analysis of the nine key symptoms found three components with an eigen value of over one, together accounting for $60 \%$ of the variance (30\% for component one; $18 \%$ component two; $12 \%$ component three). Figure 3 shows the symptoms weighting each component. Component one was distinguished by fear of weight gain, preoccupation with body weight and shape and excessive exercise. Component two comprised underweight and somatic complaints but not weight and shape concerns and negatively for binge eating. Component three comprised self-induced vomiting and binge eating and was negative for underweight.

\section{Comorbidity and medication}

The three main comorbidities (depression, anxiety and OCD) were reported as possible or definite in $86(41 \%)$ individuals, absent in $98(47 \%)$ and the remainder unknown. Comorbidity was fairly evenly distributed across diagnoses, anxiety being the most common. For 13 individuals comorbid autism-spectrum or other pervasive developmental disorder was mentioned, as were a number of other neurodevelopmental problems such as tic disorders and attention-deficit hyperactivity disorder. Other comorbidities noted included trauma and grief reactions $(n=7)$, chronic fatigue syndrome and other somatoform disorders $(n=3)$, psychosis $(n=2)$ and learning disability $(n=2)$.

\section{Management}

In total, $104(50 \%)$ were admitted to hospital (71\% of those with anorexia nervosa). Most admissions were to paediatric wards for 


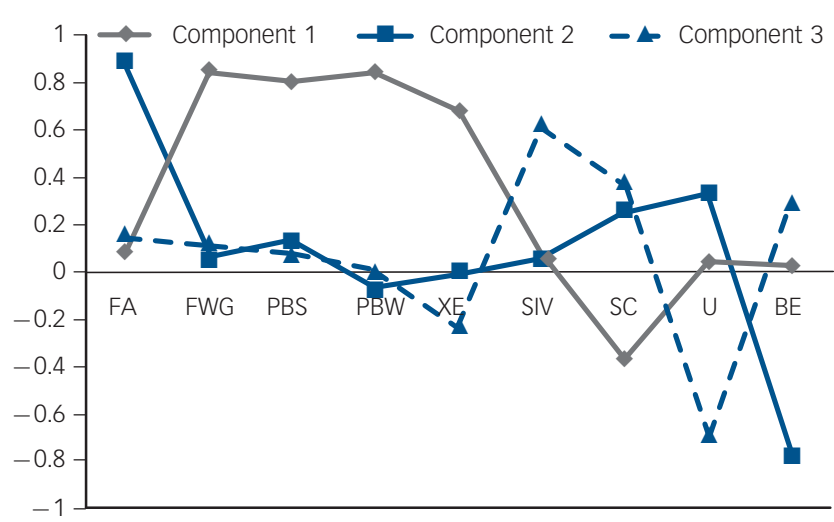

Fig. 3 Principal-components analysis showing three main components with differing symptom profiles.

FA, food avoidance; FWG, fear of weight gain; PBS, preoccupation with body shape: PBW, preoccupation with body weight; XE, excessive exercise; SIV, self-induced vomiting; SC, somatic complaints; $U$, underweight; $B E$, binge eating.

all diagnostic groups (37\% of total, $73 \%$ of all admitted); $18 \%$ of the total number required psychiatric admission. Twenty-three (11\%) individuals were fed by nasogastric tube, all from the diagnostic groups of anorexia nervosa, EDNOS or 'other'. A total of $13 \%$ were prescribed psychotropic medication, the highest proportion being in the EDNOS categories. Most commonly used were a selective serotonin reuptake inhibitor (fluoxetine for nine individuals, sertraline for four, and one not stated) or an atypical antipsychotic (olanzapine for four individuals and risperidone for eight), with one diazepam and one melatonin.

\section{1-year outcome}

Some follow-up data were reported on 178/208 individuals (86\%), although of these $11 \%$ were reported as unknown. No diagnostic group was over- or underrepresented in the follow-up data. There were no deaths at 1-year follow-up. In total, 130 (73\%) were reported as improved, $11(6 \%)$ were worse and $18(10 \%)$ unchanged. Overall, 96 (60\%) were still receiving treatment, 48 $(30 \%)$ were not and for the remainder this was unknown. It is not known whether those not receiving treatment had recovered or had dropped out of treatment. Of 178 at follow-up, only 67 were still under the care of the same clinician.

At a mean of 11.5 months after measuring initial weight, most individuals had gained weight (mean $7 \mathrm{~kg}$, range $0.2-24.9$ ). Of the nine who had lost weight, the range was from 0.2 to $14 \mathrm{~kg}$ loss (mean 4.6). Mean change in BMI at follow-up was $+2.1 \mathrm{~kg} / \mathrm{m}^{2}$.

The average length of admission reported at follow-up was 76 days (32 days for paediatric admissions), and seven individuals had been in hospital for more than 200 days by the time of follow-up. By 1 year only six children had been readmitted or admitted for the first time to hospital - six to paediatric wards and three to psychiatric in-patient units. Most children were in school, with 16 attending part time and 8 not in school. Comorbidity at follow-up was almost identical to that at baseline - data not shown.

\section{Discussion}

This study provides a contemporary estimate of the incidence of early-onset eating disorders in UK and Irish children presenting to paediatricians or child and adolescent psychiatrists, and highlights the severity and health service needs of these individuals. We found an overall incidence of eating disorders of 3/100 000 children under 13 years of age. In total, $80 \%$ presented with an anorexia nervosa-like illness; $37 \%$ met our operational definition for anorexia nervosa and a further $43 \%$ were classified as EDNOS because they did not meet underweight criteria at the time of reporting. Only $4 \%$ were identified with bulimia nervosa or other binge eating, which is likely to be an underestimate. Almost 20\% met the case definition but did not have the weight and shape concern, and are thus not classifiable by current DSM-IV criteria. Admission to hospital was required for 50\% of individuals, typically shortly after presentation.

\section{Incidence}

Direct comparison with previous UK data is limited because of differences in the age bands used and methodology. The 1999 Office for National Statistics study reported a prevalence of $0.3 \%$ for eating disorders in 11 - to 15 -year-olds, based on a single screening question, with no one in the 5- to 10-year-old age group. ${ }^{23}$

Incidence data from a general practice registry study in the early 1990s found an incidence estimate for anorexia nervosa of $0.3 / 100000$ in 0 - to 9 -year-olds and $17.5 / 100000$ in the 10 - to 19 -year-olds. For bulimia nervosa the rates were 0/100 000 and 20.5/100 000 respectively. ${ }^{24}$ Our data for 0 - to 9-year-olds was two and a half times higher (7.5/100 000). Retrospective studies from the USA and Denmark have suggested higher figures for anorexia nervosa, for example 9-27 per 100000 for 10- to 14year-old girls and 3.7 per 100000 for boys. ${ }^{25,26}$ Previous studies have been limited to anorexia nervosa and bulimia nervosa, and excluded EDNOS and other atypical presentations, which together accounted for $62 \%$ of our sample.

Two surveillance studies have used similar methodology to ours. Madden et $a l^{27}$ reported an annual incidence of 1.4 per 100000 children in Australia, half that of this UK/ROI study. The Australian study was confined to in-patients for 1 of 3 study years, and included few child and adolescent psychiatrists (2\% of respondents). Our study used a dedicated child and adolescent psychiatric surveillance system. Unpublished data from the Canadian Paediatric Surveillance Program report 2.6/100000, similar to our study. ${ }^{28}$

Importantly, our data provide a baseline from which to measure whether the incidence of eating disorders in children are really increasing as Van Son et al ${ }^{4}$ suggest, but do not at this point provide evidence for a true rise in incidence in children.

\section{Demographics and medical status}

As expected, the majority of individuals with eating disorders were female. Boys made up $18 \%$ of the overall sample, increasing to $33 \%$ of the 'other' category. This compares with $27 \%$ males overall in the Australian study. ${ }^{27}$ This may be as a result of the broader case definition used in the Australian study, resulting in a higher proportion of atypical cases. Atypical presentations and lack of awareness that these conditions can arise in young children and boys can lead to delay in referral, diagnosis and treatment. ${ }^{6,29}$ Three-quarters of girls were premenarcheal, similar to findings among in-patients in the Australian Paediatric Surveillance Unit study. $^{27}$

We found that around $50 \%$ of individuals needed to be admitted to hospital. This contrasts with hospitalisation rates of over $70 \%$ in the Australian study, a sample biased towards in-patients. Our study provides a more representative picture in terms of the burden on hospital resources for younger individuals with eating disorders. The majority $(73 \%)$ of those admitted in 
our study were admitted to paediatric units rather than psychiatric or specialist eating disorders units. The National Inpatient Child \& Adolescent Psychiatric Survey ${ }^{30}$ showed that eating disorders were the most common diagnosis among child and adolescent psychiatric in-patients in England and Wales, 9.2\% of whom were $<13$ years. The National Inpatient Child \& Adolescent Psychiatric Survey did not include children on paediatric wards. Ours are the first published data on the scale of paediatric resource used by this patient group in the British Isles. Clinical experience suggests wide variation in the confidence among paediatricians over the management of these cases. This study provides the baseline figures needed to determine whether increases in hospitalisation rates are real or perceived, and can aid planning of age-appropriate services. Furthermore, there are currently no national paediatric guidelines for the care of individuals with eating disorders.

\section{Diagnostic categories}

Diagnosis and nosology are the subject of much discussion and debate, with revisions to DSM-IV and ICD-10 pending. In particular, the category of EDNOS has been widely criticised for being too heterogeneous, ${ }^{31}$ accounting for $77.4 \%$ of all individuals diagnosed with adolescent eating disorders in the community compared with only $13 \%$ for anorexia nervosa and $10 \%$ for bulimia nervosa. ${ }^{32}$ Particular problems with the application of current diagnostic criteria for children and adolescents have also been highlighted. ${ }^{20,33}$ This study provided an opportunity to explore the nosology of early-onset cases using a symptom-based approach. Principal-components analysis, based on nine key symptoms, found that three main clinical profiles in this age group in our study accounted for $60 \%$ of the variance. Our findings support those who argue that weight status is a continuum and does not distinguish between clinical cases on other criteria. This is particularly so in children; weight status is often a reflection of adult interventions (i.e. whether the child had been fed) rather than a measure of severity of illness.

Those individuals who present with determined food avoidance in the absence of weight and shape concerns, $20 \%$ of our sample, are of less clear nosological status. Variously described as food avoidance emotional disorder ${ }^{34}$ or non-fat phobic anorexia nervosa, ${ }^{35}$ these cases might possibly be classified as anorexia nervosa on GP registers. Identification of these individuals has important implications for the development of clinical approaches to intervention, currently lacking, and for the scope of eating disorders provision.

\section{Management}

Of the total sample, $11 \%$ (22\% of in-patients) were fed via nasogastric tube, compared with $58 \%$ of in-patients in the Australian study. Furthermore, $34 \%$ were prescribed psychotropic medication in the Australian sample, compared with only $13 \%$ in our sample. The mean duration of admission in the Australian study was only 24.7 days, compared with 76 days overall and 32 days for paediatric admissions in our sample. These differences may reflect cultural differences in treatment approach and/or differences in health service organisation, as well as the bias towards studying in-patients in the Australian study. Further research is needed to understand the implications for outcome of different approaches.

\section{Risk factors and early intervention: psychiatric comorbidity}

This study enabled examination of the first phases of an eating disorder in young children, before it has become compounded by chronicity. Increasing recognition of the neurodevelopmental contributions to risk for anorexia nervosa are reflected in the proportion of individuals in our study with comorbid autismspectrum, psychotic and other developmental disorders. Prepubertal cases provide an opportunity to explore neurobiological risk factors before they are overshadowed by the major role that puberty plays.

In over $40 \%$ there was a family history of mental illness, most commonly anxiety or depression. In addition, a history of early feeding problems was reported in over $20 \%$ of individuals, across the diagnostic groups. Our study supports others that highlight the importance of family history and of early feeding problems, particularly fussy or picky eating, as risk factors for the development of early-onset eating disorders. ${ }^{36}$

One of the most concerning findings from this study was that the mean time between onset of symptoms and presentation to secondary care was 8.3 months. The follow-up data show that most hospitalisations occur in the period immediately after presentation, with very few once treatment is established. The length of illness prior to presentation and the severity of illness at presentation suggest an urgent need to improve early detection and management of these individuals. Lask et $a l^{16}$ found that a single GP consultation about eating behaviour or weight and shape concerns is a strong predictor of the subsequent emergence of anorexia nervosa.

\section{1-year outcome}

Our study is the first to report the short-term outcome in a large representative sample of individuals with childhood-onset eating disorders. Although outcome was reported as good for the majority, a significant minority (16\%) were reported as worse or unchanged at 1 year. Almost two-thirds of individuals were still in treatment, with a small number (seven) in hospital for most of the year. These data confirm that the healthcare burden of childhood eating disorders is not solely attributable to in-patient admission, and reinforces the needs to plan for long-term out-patient care. Our data suggest that the National Institute for Health and Clinical Excellence (NICE) guideline recommendation that out-patient treatment be offered typically for 6 months in the first instance and for a year after hospitalisation can reasonably be applied to children with eating disorders as well as adolescents and adults. ${ }^{12}$

\section{Strengths and limitations}

The main strengths of our study are the national representative sample, and consequently adequate cases for descriptive analysis. With the high response rate from clinicians, the inclusion of cases presenting both to paediatricians and child psychiatrists, and the encouragement of dual reporting, we are confident that we have identified over $80 \%$ of restrictive eating disorders in those under 13 presenting to secondary care in the UK and ROI in the reporting year in both the National Health Services (NHS) and independent sector.

This methodology is limited to cases seen by consultant paediatricians and child psychiatrists. Those managed by GPs, in mental health services that do not have paediatric or psychiatric involvement, by training grade or career grade clinicians, receiving alternative healthcare or those receiving purely dietetic/ nutritional care would not be identified by this methodology.

Case ascertainment in surveillance studies relies on clinician judgement and accuracy of clinician reporting. This will be more important for some data, for example binge eating and comorbidity, than for others such as weight. Binge, or loss of 
control eating is likely to be particularly underrepresented, since this would require systematic screening and clear operational criteria to detect. Data were checked for internal consistency, especially when duplicate reports were available. For example, individuals reported as both in early puberty and as postmenarcheal were reassigned to mid-late puberty.

\section{Implications}

The 2004 NICE guidelines ${ }^{12}$ on the treatment of eating disorders highlight the need for developmentally appropriate care for young people with eating disorders, and the importance of coordination between professionals involved in their care. Many eating disorder services are specifically aimed at adolescents. Our study reaffirms the importance of considering the needs of children with eating disorders, in addition to and separately from those of adolescents, rather than simply lowering the age range of adolescent services. In particular, the role of paediatric services needs clarification and coordination between professionals in the management of these individuals, for example through the use of care protocols. Childhood eating disorders are not quick or easy to treat, and for a minority may be the start of a severe and enduring illness, with a mortality comparable with some forms of leukaemia. There is an urgent need to improve efforts directed towards early detection and intervention, with the expectation that this will improve prognosis. ${ }^{37}$

Dasha E. Nicholls, MBBS, MD, Department of Child \& Adolescent Mental Health Great Ormond Street Hospital for Children and UCL Institute of Child Health, University College London; Richard Lynn, MSC, UCL Institute of Child Health, University College London and the Royal College of Paediatrics and Child Health Research Unit, London; Russell M. Viner, MBBS, PhD, UCL Institute of Child Health, University College London, UK

Correspondence: Dasha E. Nicholls, Department of Child \& Adolescent Menta Health, Great Ormond Street Hospital for Children NHS Trust, London, WC1N 3JH. Email: D.Nicholls@ich.ucl.ac.uk

First received 12 Apr 2010, final revision 20 Aug 2010, accepted 22 Nov 2010

\section{Funding}

The study was funded by the Harold Hyam Wingate Foundation.

\section{Acknowledgements}

We thank the British Paediatric Surveillance Unit (BPSU), supported by the Department of Health, for facilitating the data collection and the reporting clinicians, particularly those who completed the questionnaires. Thanks also to Liz Atkinson in the Membership Relations Department of the Royal College of Psychiatrists and to all members of the Child and Adolescent Psychiatry Faculty for their support, and to Sloane Madden and the team at Westmead Hospital, Sydney.

\section{Appendix}

\section{Operational criteria for diagnostic grouping for cases meeting the case definition}

Anorexia nervosa

Weight $<85 \%$ median body mass index/age.

Determined food avoidance.

Weight and shape concerns.

Compensatory behaviours - optional but confirmatory.

If reached menarche, must have amenorrhoea.

\section{Bulimia nervosa}

$>85 \%$ ideal body weight.

Bingeing.

One or more compensatory behaviour.

Weight and shape concerns.
Eating disorder not otherwise specified (EDNOS)

(a) Binge eating (binge eating disorder)

Bingeing but no compensatory behaviours or food avoidance.

Weight and shape concerns present.

(b) EDNOS

All other cases not meeting criteria above but with the presence of weight and shape concerns.

Other

Meets the case definition but not the inclusion criteria for one of the diagnoses above.

\section{References}

1 Currin L, Schmidt $\mathrm{U}$, Treasure J, Jick $\mathrm{H}$. Time trends in eating disorder incidence. Br J Psychiatry 2005; 186: 132-5.

2 Hoek HW, van Hoeken D. Review of the prevalence and incidence of eating disorders. Int J Eat Disord 2003; 34: 383-96.

3 Lucas AR, Beard CM, O'Fallon WM, Kurland LT. Fifty year trends in the incidence of anorexia nervosa in Rochester, Minnesota: a population-based study. Am J Psychiatry 1991; 148: 917-22.

4 van Son GE, van Hoeken D, Bartelds Al, van Furth EF, Hoek HW. Time trends in the incidence of eating disorders: a primary care study in the Netherlands. Int J Eat Disord 2006; 39: 565-9.

5 Bryant-Waugh R, Lask B. Eating disorders in children. J Child Psychol Psychiatry 1995; 36: 191-202.

6 Jacobs BW, Isaacs S. Pre-pubertal anorexia nervosa: a retrospective controlled study. J Child Psychol Psychiatry 1986; 27: 237-50.

7 Gowers SG, Crisp AH, Joughin N, Bhat A. Premenarcheal anorexia nervosa J Child Psychol Psychiatry 1991; 32: 515-24.

8 Arnow B, Sanders MJ, Steiner H. Premenarcheal versus postmenarcheal anorexia nervosa: a comparative study. Clin Child Psychology Psychiatry 1999; 4: 403-14.

9 Fosson A, Knibbs J, Bryant-Waugh R, Lask B. Early onset anorexia nervosa. Arch Dis Child 1987; 62: 114-8.

10 Peebles R, Wilson JL, Lock JD. How do children with eating disorders differ from adolescents with eating disorders at initial evaluation? J Adolesc Health 2006; 39: 800-5.

11 Cooper PJ, Watkins B, Bryant-Waugh R, Lask B. The nosological status of early onset anorexia nervosa. Psychol Med 2002; 32: 873-80.

12 National Institute for Health and Clinical Excellence. Eating Disorders: Core Interventions in the Treatment and Management of Anorexia Nervosa, Bulimia Nervosa and Related Eating Disorders. NICE, 2004.

13 Goodman R, Ford T, Simmons H, Gatward R, Meltzer H. Using the Strengths and Difficulties Questionnaire (SDQ) to screen for child psychiatric disorders in a community sample. Int Rev Psychiatry 2003; 15: 166-72.

14 House J, Eisler I, Simic M, Micali N. Diagnosing eating disorders in adolescents: a comparison of the eating disorder examination and the development and well-being assessment. Int J Eat Disord 2008; 41: 535-41.

15 Bjork T, Clinton D, Norring C. Reasons for non-participation in follow-up research on eating disorders. Eat Weight Disord 2006; 11: 147-53.

16 Lask B, Bryant-Waugh R, Wright F, Campbell M, Willoughby K, Waller G. Family physician consultation patterns indicate high risk for early-onset anorexia nervosa. Int J Eat Disord 2005; 38: 269-72.

17 Lynn RM, Pebody R, Knowles R. Twenty years of active paediatric surveillance in the the UK and Republic of Ireland. Euro Surveill 2006; 11: E060720.

18 American Psychiatric Association. Diagnostic and Statistical Manual of Mental Disorders (4th edn) (DSM-IV). APA, 1994.

19 World Health Organization. The ICD-10 Classification of Mental and Behavioural Disorders: Clinical Descriptions and Diagnostic Guidelines. WHO, 1992.

20 Bravender T, Bryant-Waugh R, Herzog D, Katzman D, Kreipe RD, Lask B, et al. Classification of child and adolescent eating disturbances. Workgroup for Classification of Eating Disorders in Children and Adolescents (WCEDCA). Int J Eat Disord 2007; 40 (suppl): S117-22.

21 Cole TJ, Freeman JV, Preece MA. Body mass index reference curves for the UK, 1990. Arch Dis Child 1995; 73: 25-9.

22 World Health Organization. Physical status: the use and interpretation of anthropometry. Report of a WHO Expert Committee. World Health Organization Technical Report Series 1995; 854: 1-452. 
23 Ford T, Goodman R, Meltzer H. The British Child and Adolescent Mental Health Survey 1999: the prevalence of DSM-IV disorders. J Am Acad Child Adolesc Psychiatry 2003; 42: 1203-11.

24 Turnbull S, Ward A, Treasure J, Jick H, Derby L. The demand for eating disorder care. An epidemiological study using the general practice research database. Br J Psychiatry 1996; 169: 705-12.

25 Pfeiffer RJ, Lucas AR, Ilstrup DM. Effect of anorexia nervosa on linear growth Clin Pediatr 1986; 25: 7-12.

26 Joergensen J. The epidemiology of eating disorders in Fyn County, Denmark, 1977-1986. Acta Psychiatr Scand 1992; 85: 30-4

27 Madden S, Morris A, Zurynski YA, Kohn M, Elliot EJ. Burden of eating disorders in 5-13-year-old children in Australia. Med J Aust 2009; 190: 410-4.

28 Canadian Paediatric Society. Canadian Paediatric Surveillance Program. 2005 Results. Canadian Paediatric Society, 2006 (http://www.cps.ca/English/ surveillance/cpsp/Studies/2005Results.pdf)

29 Bryant-Waugh R, Lask B, Shafran R, Fosson A. Do doctors recognise eating disorders in children? Arch Dis Child 1992; 67: 103-5.

30 Department of Health. National Inpatient Child and Adolescent Psychiatric Survey (NICAPS). TSO (The Stationery Office), 2002 (http://web.archive.org/ web/20040727185457/www.rcpsych.ac.uk/cru/complete/NICAPS+ report+.pdf)
31 Thomas JJ, Vartanian LR, Brownell KD. The relationship between eating disorder not otherwise specified (EDNOS) and officially recognized eating disorders: meta-analysis and implications for DSM. Psychol Bull 2009; 135 407-33.

32 Machado PP, Machado BC, Goncalves S, Hoek HW. The prevalence of eating disorders not otherwise specified. Int J Eat Disord 2007; 40: 212-7.

33 Nicholls D, Chater R, Lask B. Children into DSM IV don't go: a comparison of classification systems for eating disorders in childhood and early adolescence. Int J Eat Disord 2000; 28: 317-24.

34 Nicholls D, Bryant-Waugh R. Eating disorders of infancy and childhood: definition, symptomatology, epidemiology, and comorbidity. Child Adolesc Psychiatr Clin N Am 2009; 18: 17-30.

35 Becker $A E$, Thomas JJ, Pike KM. Should non-fat-phobic anorexia nervosa be included in DSM-V? Int J Eat Disord 2009; 42: 620-35.

36 Nicholls DE, Viner RM. Childhood risk factors for lifetime anorexia nervosa by age 30 years in a national birth cohort. J Am Acad Child Adolesc Psychiatry 2009; 48: 791-9.

37 Katzman DK, Golden NH, Neumark-Sztainer D, Yager J, Strober M. From prevention to prognosis: clinical research update on adolescent eating disorders. Pediatr Res 2000; 47: 709-12.

\section{psychiatry in the movies}

\section{Invasion of the Body Snatchers (Don Siegel, 1955)}

\section{Trevor Turner}

'A strange neurosis ... evidently contagious ... people worrying about what's going on in the world', that is how the contented, pipe-smoking, 1950s Californian small town psychiatrist explains what is happening in Santa Mira. Ten or more patients referred complaining of their relatives somehow being changed - and the hero, a local doctor/GP played by the strong-faced actor Kevin McCarthy (a great name for a McCarthy era paranoid thriller) cannot work out what is going on. He is first seen at the city emergency hospital, as a screaming, dishevelled paranoid psychotic ('you fools I'm not crazy . . I'm a doctor too . . . you must understand me ... I'm not crazy'). He recounts the story in a prolonged voice-over flashback. The audience is a sceptical emergency clinic physician, a policeman, and 'Dr Hill from the state mental hospital'. Is Kevin mad, even though he starts to talk quite calmly, or are there really large leafy pods turning into people and replacing them with emotionless automatons, looking like people but with 'something missing'?

Given the liberal way our doctor hero hands out tablets, some sleeping meds to young Jimmy who has 'got the crazy idea his mother isn't his mother', as well as things to keep awake on, for him and his beautifully coutured girlfriend (her strapless dress is a joy to behold) you might well think he is part of the problem. Were the film to be part of a psychiatric exam you would mark down anyone who did not put amphetamine-induced psychosis at the top of the differential diagnosis. However, as he and the story unravel we delight in the clothes, cars and cocktails of middle-class America, and the nightmare dislocation of what happens when 'something evil has taken possession of the town', with people having 'no difference you can actually see'. Increasingly perplexed, the doctor hero faces cancelled appointments, a friend having 'I guess you'd call it a delusion', such as to think 'Uncle Ira isn't her uncle, he's an impostor, someone who only looks like Uncle Ira', increasing alarm as to who to trust, and of course casual references to his friend the local psychiatrist as a 'witchdoctor'. Eventually he has to flee somewhere into the surrounding hills, clinging onto his girlfriend who bravely runs along behind him in high heels. Before this he admits, 'I'm just a general practitioner, love is handled by specialists'.

Fast-paced, economical, black and white, a mere 80 minutes long, Invasion is not just a classic paranoid thriller, it is also an accidental archive of the 1950s medical practice and a brilliant exposition of the Capgras syndrome, en masse. Most viewers read it as either a trumpet call to the dangers of a communist takeover ('there's no emotion, just the pretence of it') or a coded warning of the dangers of McCarthyite witch-hunts ('is he Uncle Ira or isn't he Uncle Ira?'). Not overtly a film about psychiatry or its practices, like so many police and sci-fi melodramas it uses a psychiatric condition as the framework for plot, character and exposition. As writers became more confident with this kind of material, drawn from our very own casebooks, they no longer needed a doctor or psychiatrist actually in the picture. The investigating cop, for example Jack Nicholson in Roman Polanski's Chinatown (1974), unravels the history and diagnosis thanks to his intuition and police know-how, but he was just dealing with child abuse.

However you take Invasion, it is not only fine entertainment, but also great fun for psychiatrists to watch. Its implicit assurance that psychiatrists probably know much more than anyone else about how the world works and why people do certain things is also rather refreshing. After all, 'Dr Hill from the state mental hospital' does let our hero have his say. 